\title{
ENTRE A INSTITUIÇÃO DE ENSINO E O MERCADO DE CONSUMO: A LEITURA DE BEST- SELLERS POR ACADÊMICOS DE LETRAS
}

\author{
Vera Helena Gomes Wielewicki (UEM) \\ Daiane da Silva Lourenço (UTFPR)
}

Resumo: Este trabalho apresenta os resultados de uma pesquisa de cunho etnográfico com foco nas preferências de leituras de acadêmicos de um curso de Letras. Os dados coletados demonstram o interesse pela leitura de best-sellers fora da instituição de ensino e a influência da mídia sobre as escolhas de leitura e concepções de literatura dos participantes.

Palavras-chave: Best-sellers, preferências de leituras, jovens leitores, mercado editorial, concepções de literatura.

Abstract: This paper presents the results of an ethnographic research focusing on the reading preferences of undergraduates in a Letras course. The data collected reveals an interest in reading bestsellers outside the educational institution and the influence of media on the reading choices and literature conceptions of the participants.

Keywords: Best-sellers, reading preferences, young readers, publishing industry, literature conceptions.

O aumento de leituras de obras, por parte de leitores jovens, tanto de leitores ainda na educação básica quanto de acadêmicos, revela que, ao invés de lerem apenas o que a escola ou a universidade pede, desenvolvem seus próprios gostos e tendem a escolher o que leem fora de tais instituições. O interesse em averiguar as histórias de leituras de um grupo de jovens e seu crescente interesse pelo ato de ler romances levou-nos a elaborar esta 
pesquisa, contribuindo para o campo de estudos sobre formação de leitores.

Com uma matéria intitulada "Uma geração descobre o prazer de ler", a Revista Veja, número 2217, edição de 18 de maio de 2011, enfatiza que romances comerciais têm iniciado jovens na leitura e os conduzido a leituras mais elaboradas. Acrescenta também que, no Brasil, na virada do século XX para o XXI, acreditava-se que o hábito de ler desapareceria, devido a fatores como o ensino básico em declínio, o pouco apreço dado à instrução, a falta de bibliotecas públicas e o alto preço dos livros. Ao contrário das expectativas, uma nova e robusta geração de leitores vem surgindo no país, a partir de sucessos globais, geralmente produzidos em língua inglesa e traduzidos para nossa língua: séries como Harry Potter, Crepúsculo e Percy Jackson. Milhares de títulos têm sido vendidos para o público infantojuvenil, mas também para um público mais velho: romances de autoajuda, com histórias românticas (como de Nicholas Sparks) ou recontando a história do Brasil (como 1808, 1822, Guia Politicamente Incorreto da História do Brasil).

Como são poucos os pesquisadores que se voltam para os objetos de leitura escolhidos pelos alunos, ao contrário dos "indicados" pelos professores, suas percepções enquanto 
leitores literários são praticamente desconhecidas. Por essa razão, ao observarmos que alguns acadêmicos de um curso de Letras, Português-Inglês, de uma universidade pública, buscavam outras literaturas, além da brasileira, para ler fora da universidade, procuramos realizar uma pesquisa a fim de conhecer suas preferências de leitura. Diante da lista de títulos de romances citados como lidos no último ano, buscamos coletar outros dados dos participantes da pesquisa, como o processo das escolhas de leituras.

Consideramos importante abordar as percepções de tais leitores jovens, professores em formação. Por serem acadêmicos de um curso de Letras, têm aulas de teoria literária, logo são direcionados pelos professores para leituras de cânones literários. No entanto, muitos citaram best-sellers que leem fora da universidade. Diante disso, apresentamos neste artigo algumas características de romances best-sellers e uma leitura das perspectivas de participantes da pesquisa acerca de suas escolhas de obras. Escolhas de leituras que realizam enquanto professores em formação e, ao mesmo tempo, como jovens brasileiros, por isso estão entre a instituição de ensino e o mercado de consumo. 


\section{ROMANCES BEST-SELLERS: POPULARES ENTRE JOVENS BRASILEIROS, MARGINAIS PARA INSTITUIÇÕES DE ENSINO}

Apesar de tantas críticas negativas a respeito de obras consideradas best-sellers, os adolescentes continuam lendoas. Eles sabem que são consideradas "menores", pois escutam conselhos dos professores para que leiam os clássicos e aprendam a apreciar a Literatura, ao invés de dedicar horas a romances comerciais. Entretanto, os best-sellers parecem ser a leitura mais interessante no momento. Não quer dizer que os jovens não leiam o cânone, o fazem porque têm contato com ele semanalmente na escola, no livro didático, na universidade. Entretanto, como apresenta Rocco (1992) em sua pesquisa sobre leituras de adolescentes, tais sujeitos afirmam gostar de ler, mas não na escola. Nessa, "só o fazem quando se trata de exigência obrigatória da área de Português. Gostam de ler, no entanto, fora da escola" (ROCCO, 1992, p.71, grifo do autor). Quanto as suas preferências de leitura, estas, muitas vezes, são contrárias às indicações de professores e pais. Pais e professores consideram que suas escolhas de leitura não são produtivas, enquanto os cânones são considerados pela maioria dos alunos "chatos", lidos para cumprir exigências escolares (ROCCO, 1992).

A falta de maturidade dos alunos é o principal argumento dos professores para explicar suas opções de leitura, já que 
aqueles parecem ter argumentos diversos para preferir romances comerciais. São argumentos de sujeitos que ainda não têm conhecimento de aspectos literários, com pouca experiência para entender textos complexos, e que estão interessados em entretenimento.

A partir de sua pesquisa, Rocco (1992) expõe as quatro principais críticas negativas dos estudantes aos clássicos: a) enredo "monótono", "cansativo", "sem ritmo"; b) "linguagem difícil", "vocabulário complicado", "linguagem cheia de rodeios", diferente da que usam ou da que estão acostumados fora da escola; c) extensão dos textos e das letras muito pequenas; d) gosto, afirmam "não gosto, porque não gosto e está acabado". Como professoras, já ouvimos pelo menos uma dessas críticas feitas por adolescentes na sala de aula.

Em uma pesquisa feita uma década depois, por Mafra (2003), a respeito das leituras de alunos do ensino básico, o grupo de estudantes entrevistados também afirmou o consumo de uma leitura não oficializada e não aceita pela escola. Ao contrário da crença de que os adolescentes não leem, sua pesquisa comprova que têm lido mais do que imaginam os professores, mas fora da escola. Leem no sentido de prazer barthesiano, buscando a satisfação. 
Mesmo diante de repreensões de professores, os bestsellers têm iniciado os adolescentes na leitura. Ocupando as margens do ensino, esses romances já adquiriram espaço na sociedade brasileira. Diante de tal constatação, Mafra (2003) afirma que "'Suja', ela [literatura de massa] já adentrou o recinto. Mais do que isso, ela já se incorporou ao ambiente, é conhecida e, em muitos casos, íntima da grande maioria. Mas continua-se a não reconhecer sua presença, em nome da higiene e da saúde do ambiente". A crítica literária insiste em marginalizar esses romances, como forma de defender o cânone como patrimônio cultural. Não há mais como negar a popularidade dos best-sellers. Podemos, entretanto, tentar guiar essas leituras dos adolescentes, para que não sejam totalmente vazias.

Os sujeitos da pesquisa de Mafra justificam o interesse por best-sellers explicando que estão "em alta" no mercado, são atuais, são o principal assunto de grupos de amigos, já os romances clássicos descrevem épocas passadas e têm vocabulário complicado.

Acreditamos que a indústria editorial tem cada vez mais investido em obras que atendam às expectativas de seu público leitor, por isso, como resultado, tantos romances têm atingido sucesso. A preocupação não é com a literariedade, com a forma, com o estilo, mas com o conteúdo, empregado 
de uma maneira que envolva e desperte a curiosidade do leitor, e que o mesmo sinta a necessidade de ler o volume seguinte, e o próximo, e o próximo. A fórmula parece estar dando certo, resultando em uma boa quantia de capital, tanto que antes mesmo do lançamento de alguns volumes, como o último da série Harry Potter, diversos leitores já haviam reservado o seu, enquanto outros faziam parte de filas imensas em frente às livrarias, à espera do lançamento e da oportunidade de ter em mãos o seu próprio livro.

De acordo com as pesquisas que realizamos, o interesse pela leitura de um best-seller começa pelo exterior da obra: capa, título, ilustrações, resenha, resumo. Os próprios jovens afirmam que escolhem suas leituras a partir de textos da orelha, contracapa, críticas (VERSIANI, 2003). Quanto ao interior, a linguagem é acessível a qualquer leitor; o texto não provoca estranheza; o conteúdo é envolvente, abordando temas da faixa etária do leitor; a fábula é simples; o texto segue padrões formais; a leitura é feita como entretenimento; o texto faz as pessoas esquecerem a realidade; por isso os best-sellers são rapidamente consumidos.

Além desses elementos básicos, ainda é possível citar outros. Sodré (1985) sugere que nos romances comerciais é constante a presença do mito heroico. A emoção dos leitores ainda é despertada diante de um super-herói 
corajoso e benfeitor. Presente em enredos literários desde a antiguidade, este tipo de herói deixou de ser construído por muitos escritores com o surgimento do modernismo e seu herói fragmentado. O mito heroico parece não caber mais na literatura contemporânea, devido a tantas mudanças sociais, econômicas, políticas e ideológicas, contudo ainda conquista muitos leitores e espectadores, por meio de narrativas impressas, teatros, filmes e séries de TV.

Segundo Sodré (1985), o herói que ainda conquista a massa realiza façanhas, como lutar contra monstros e vencer. Atualmente os monstros têm sido substituídos por bruxos do mal, vampiros, deuses ambiciosos, lobisomens, entre outros. Em todos os casos, o herói sempre triunfa. Além da façanha, este também é um ser soberano: "o herói não peca jamais contra a lealdade, a franqueza, a determinação"; "sua coragem costuma ser também inabalável"; "o herói colocase no grupo social como uma individualidade solidária e redentora, isto é, como um salvador ou justiceiro"; "sempre disposto a salvar o mundo ou transformá-lo de algum modo através de seus poderes extraordinários" (SODRÉ, 1985). Já o herói da literatura canônica moderna foge a tais características. O herói moderno tem aparecido em alguns romances como um ser fragmentado, impossível de ser enquadrado nas características anteriormente citadas, 
pois não segue um "modelo". A luta do bem contra o mal se tornou um artifício da indústria cultural.

Na literatura comercial, ofoco principalé o conteúdo. Por meio do conteúdo, os romances podem ser classificados: romance policial; romance sentimental; romance de terror; romance de aventura; ficção científica; romance de suspense; romance de espionagem. Cada um desses gêneros populares tem peculiaridades que pretendem envolver o leitor: o romance policial insere na narrativa um crime que precisa ser desvendado; o romance sentimental apresenta um casal que enfrenta complicações para ficarem juntos; o romance de aventuras tem desafios que devem ser superados por seus personagens. De maneira geral, para Sodré, os romances comerciais são constituídos pelo mito heroico, informações atuais a respeito do conteúdo abordado, pedagogismo (ideologias passadas ao leitor) e presença da literatura culta, lida por um ou mais personagens.

Outro caráter comum dos romances comerciais é a pouca durabilidade, a efemeridade (ECO, 1979). Assim como os produtos industriais consumidos cada vez mais rápidos (celulares, computadores, televisores), também os romances produzidos para consumo são passageiros. 
Durante um período, atendem à necessidade dos leitores, estão na mídia com grande sucesso, mas em alguns meses são substituídos por outros romances, agora considerados mais interessantes.

As características apontadas são constantes nos bestsellers e são as que despertam o interesse de leitores adolescentes brasileiros. Os leitores adolescentes, antes tidos como não leitores, buscam essas obras nas bibliotecas públicas e escolares e, os que têm condições financeiras, frequentam mensalmente as livrarias a fim de adquirir os romances que querem ler e depois emprestá-los aos amigos para compartilharem leituras.

Esses romances "aliciaram milhões de leitores, ensinandoIhes desde cedo o prazer da leitura" (PAES, 1987, p.69). Não ousamos afirmar se a leitura de best-sellers é "boa" ou "ruim". Acreditamos que toda obra depende da recepção de cada leitor, que pode crescer ou não com a leitura realizada, que pode continuar lendo apenas best-sellers ou pode desenvolver interesses por obras "eruditas". Acreditamos que nenhuma leitura consegue "prejudicar" ou "edificar" um ser humano por si só.

A popularidade e a marginalização dos best-sellers, características que acompanharam o gênero romance ao 
longo dos séculos e resistiram até o início do século XXI, são resultados da influência da atual indústria cultural. As obras seguem padrões, já mencionados, que suscitam e mantêm o interesse dos leitores jovens. As características de romances best-sellers e sua relação com a indústria cultural são importantes para entendermos as perspectivas dos participantes da pesquisa e suas preferências de leitura.

\section{PARTICIPANTES DA PESQUISA E METODOLOGIA}

O grupo de participantes da pesquisa é formado por 76 estudantes de um curso de Letras, Português-Inglês, de uma universidade pública que se dispuseram a responder aos questionários e nos autorizaram a utilizar as informações fornecidas. No segundo semestre de 2010, responderam aos questionários 3 alunos do segundo ano, 22 alunos do terceiro ano e 3 alunos do quarto ano. Em março de 2011, coletamos dados de 48 alunos do primeiro ano. De todos esses participantes, 17 disponibilizaramse a participar de uma entrevista individual gravada em áudio. A maioria dos respondentes tem idade entre 1763 anos. No primeiro ano, entretanto, prevalece a faixa etária de 17 a 25 anos. Nas outras turmas predominam estudantes entre 20 e 28 anos. Dos 76 respondentes, 57 são do sexo feminino e 19, masculino. 
Devido ao interesse em compreender a circulação de literaturas estrangeiras entre alunos de um curso de Letras, coletar dados e interpretá-los, este trabalho procurou seguir procedimentos metodológicos de uma pesquisa de cunho etnográfico.

A etnografia foi inicialmente desenvolvida por antropólogos para estudar a cultura e a sociedade (ANDRÉ, 1995). Nos estudos antropológicos, esse conjunto de técnicas é usado para coletar dados sobre hábitos, costumes, crenças de um grupo específico, os quais depois são relatados por meio da descrição. Segundo André (1997), a partir do final dos anos 70, pesquisadores da área da educação demonstraram interesse pela etnografia e passaram a aplicá-la em seus trabalhos, com o objetivo de interpretar a(s) perspectiva(s) adotada(s) pelos participantes. Em nossa pesquisa, a fim de interpretar a percepção dos participantes, empregamos instrumentos de pesquisa associados à etnografia: observação do participante, entrevistas, questionários e interpretação dos dados.

Nos meses de outubro e novembro de 2010, aplicamos o Questionário 1 (focando hábitos e preferências de leitura), o Questionário 2 (aspectos socioeconômicos) e Questionário 
3 (concepções de leitura, leitor e literatura) para alunos do segundo, terceiro e quarto ano de Letras e, em março de 2011, para estudantes do primeiro ano. No período abriljunho de 2011, realizamos entrevistas semiestruturadas, gravadas em áudio, abordando suas concepções.

Para a coleta e análise de dados, empregamos a técnica da triangulação, com o objetivo de abranger a máxima amplitude na descrição, explicação e compreensão da pesquisa (TRIVIÑOS, 1987). Nessa técnica, diversas fontes são utilizadas para a coleta de dados, recorrendo a diferentes olhares para o mesmo objeto. Em nosso caso, empregamos a observação do participante, os questionários e as entrevistas. As fontes diversas favorecem a reflexão e a interpretação mais confiável da cultura dos participantes devido à extensão do corpus coletado.

\section{A CIRCULAÇÃO DE OBRAS LITERÁRIAS ENTRE OS PARTICIPANTES DA PESQUISA}

O primeiro questionário aplicado requisitou, dentre outras informações, uma lista de obras lidas sem terem sido indicadas pela universidade. O grupo de acadêmicos de Letras citou ao todo 178 títulos lidos. Os estudantes do primeiro ano apresentaram maior quantia de obras lidas, enquanto nos outros anos alguns chegaram a justificar a falta de ou a pouca 
leitura devido ao tempo livre limitado por causa das leituras exigidas pelo curso. Os estudantes do primeiro ano, no início do ano letivo, ainda não estão tão envolvidos com as leituras acadêmicas. Das obras citadas, apenas 74 títulos são de literatura brasileira, enquanto 104 de estrangeiros. Os títulos brasileiros citados são, em sua maioria, textos consagrados, tais como: A Hora da Estrela, Dom Casmurro, Fogo Morto, Macunaíma, O Alienista, Vidas Secas. Contudo, best-sellers nacionais também são mencionados: Verônica Decide Morrer, O Vendedor de Sonhos, O Alquimista, entre outros. Em meio aos títulos estrangeiros, há menções a clássicos e a obras mais vendidas. No entanto, as últimas prevalecem. Dos 104, 79 originalmente em língua inglesa (Canadense, Estadunidense, Britânica, Australiana, Irlandesa). Os alunos variam suas leituras entre Shakespeare, Jane Austen, Ernest Hemingway, Charles Dickens, Alice Walker e escritores que produzem para o consumo. Os best-sellers mais lidos são, respectivamente: A Cabana (William P. Young), Crepúsculo (Stephanie Meyer), Eclipse (Stephanie Meyer), O Caçador de Pipas (Khaled Hosseini); Marleye Eu (John Grogan), A Menina que Roubava Livros (Markus Zusak), Amanhecer (Stephanie Meyer). Apesar de estarem em um curso de Letras de licenciatura dupla, grande parte de tais leituras é realizada por meio da versão traduzida. 
O questionário aplicado possibilitou averiguarmos as influências que tais sujeitos receberam para realizar suas escolhas de objetos de leitura, questionando se preferem obras nacionais ou estrangeiras e o que consideraram ao escolherem os livros.

Os estudantes de Letras afirmam preferir literatura nacional (30 indicações), enquanto as literaturas estrangeiras foram indicadas 24 vezes, e 16 sujeitos leem as duas, sem estabelecer uma preferência entre uma ou outra. Os outros estudantes não opinaram. Sendo assim, apesar de o número de obras estrangeiras citadas ter sido maior do que o de nacionais, muitos dizem preferir a literatura brasileira por razões apontadas, como: a falta de contato com literaturas estrangeiras; pela imposição desta no Ensino Médio; maior conhecimento de obras nacionais; falta de instrução de professores para a leitura de obras estrangeiras; pela nossa realidade estar inserida no enredo. Já a preferência por literatura estrangeira é justificada pelo contato com outras culturas, pelo seu estilo, pela linguagem de fácil compreensão, por abordar temas interessantes, pela influência de amigos e mídia.

Diante das justificativas da preferência pela literatura estrangeira, percebemos que o conceito desta apresenta- 
se distorcido do propagado pela crítica literária, pois, para muitos estudantes do curso de Letras, esta literatura é constituída apenas por best-sellers. Dentro desse grupo de leitores, tal literatura é vista como constituída por linguagem simples, temas interessantes (aventura, suspense, mistério) e presente na mídia. As influências de jovens leitores são maiores sobre os pesquisados do que as da comunidade universitária.

Interessante destacar que, no primeiro ano de Letras, com a maioria dos estudantes entre 17-26 anos de idade, a indicação desta literatura prevaleceu com 17 indicações, contra 16 nacionais, ao contrário dos outros grupos que preferem as nacionais. A literatura estrangeira citada por esses estudantes que, em sua maioria, recentemente deixaram o Ensino Médio e ainda não têm contato com discussões sobre teoria literária, é a "de mercado". Já os outros estudantes, dos anos subsequentes, parecem ter maior receio em citá-las, pois sabem que é uma literatura que não é aceita no contexto universitário e têm maior consciência de sua produção para consumo.

A indicação de amigos e os seus comentários sobre as obras prevaleceram como a principal razão para realizar uma leitura (44 indicações), pois os estudantes afirmam que sua 
curiosidade é despertada. As indicações são tanto de obras clássicas, quanto de best-sellers. Sendo assim, o principal fator para a escolha de uma obra para a leitura pode ser considerado o grupo de amigos.

Além da indicação de amigos, outros motivos são citados, como: o enredo interessante (12 indicações), a preferência pelo autor (10), o interesse pelo tema abordado (8), o título (7), o filme baseado no livro (7), a preocupação com a formação (7), o gênero (romance, ficção, aventura, fantasia) (6), o resumo da obra (6), obra presenteada (4), livros clássicos (4). Dentre essas justificativas, algumas são resultado da influência do mercado editorial para que as obras sejam vendidas, como o título, o resumo, o enredo e a produção fílmica. Além dessas, outras razões aparecem com menos frequência nas respostas: por serem contemporâneos (3), a crítica do livro (2), evento na faculdade (2), continuação da saga (2), fatos reais (2), trabalho (2), mídia (2), linguagem fácil (2), vestibular (1). A preocupação com a formação enquanto professor de literatura, buscando ler obras clássicas e que contribuirão para a atual e/ou futura atuação dos sujeitos, é destacada por alguns estudantes. No entanto, muitos afirmam ter pouco tempo livre devido à quantidade de leituras exigidas pela universidade e, quando se trata de leituras extras, o best-seller prevalece, como forma de distração, passatempo. 
A análise das respostas sobre as escolhas dos sujeitos pesquisados levanta dados que correspondem à seguinte hipótese levantada por Mury (1974): os interesses literários cotidianos resultam da individualidade de cada pessoa somada às influências exteriores que recebe. Os alunos sujeitos demonstram interesses que são permeados por outros sujeitos (amigos, familiares, universidade, mídia). As respostas às questões abertas demonstram uma relação estreita entre a maioria dos participantes da pesquisa e a indústria cultural ${ }^{1}$.

Também perguntamos aos participantes da pesquisa: "Você tem mais interesse por obras nacionais ou estrangeiras? Por quê?". As respostas dos professores em formação permitem-nos chegar a algumas conclusões quanto ao conceito de literatura estrangeira dos alunos-participantes.

Há alguns estudantes que justificam sua preferência por considerarem relevante a questão cultural. Vendo-a como uma fonte de conhecimento sobre outra cultura:

Estrangeiros, pois adoro conhecer as culturas de outros povos e acredito que lendo livros estrangeiros poderei "viajar" para outros locais. (Celeste, 17 anos)

Estrangeiras. Gosto da literatura nacional, mas amo a possibilidade de um contato

1 A utilização da cultura como mercadoria é chamada de "indústria cultural" por Horkheimer e Adorno (1978). 
maior com outras culturas por meio de obras estrangeiras. (Vagner, 20 anos)

Por outro lado, há acadêmicos que relacionam a literatura estrangeira a uma leitura prazerosa, estimulada pela mídia. Em outras palavras, sua visão a esta literatura parte dos best-sellers:

Geralmente leio estrangeiros, devido comentários de amigos e mídia. (Cláudia, 19 anos)

Estrangeiros, pois são mais simples de ler e geralmente os temas chamam mais minha atenção. (Fábio, 20 anos)

Estrangeiras. Gosto do estilo, digo, de como é escrito, as obras nacionais, pelo menos as que li, têm uma linguagem "dura", torna o livro difícil de ler, uma leitura arrastada. (Pedro, 27 anos)

Esta última visão de literatura estrangeira nos parece restrita, pois, além dos best-sellers, também há outros textos, como os clássicos e os textos pós-coloniais. Isso mostra que a visão para esta literatura, do mercado editorial, tende a repercutir mais entre os jovens do que a dos especialistas. A respeito disso, Becker (2003) afirma que está havendo a disseminação do consumismo entre os jovens, o que os leva à passividade e à alienação, pois fazem o que está na "moda", imitando os amigos. Como tais jovens estão inseridos em um grupo de amigos que 
leem obras em voga na mídia, suas preferências de leituras são influenciadas.

As entrevistas realizadas nos fornecem mais dados nesse sentido. A mesma pergunta sobre a preferência por obras brasileiras ou estrangeiras foi feita aos 17 participantes entrevistados. Alguns responderam:

Ah, porque são temas mais legais, mais interessantes, mais atuais. Literatura brasileira só tem tema de romance, do século I e II [risadas]. Literatura muito antiga, histórias antigas, temas muito antigos. E a literatura estrangeira não, sempre está tendo lançamentos de temas atuais. Tem muito mais lançamento de literatura estrangeira do que brasileira, não concorda? E as obras brasileiras não são divulgadas. Aqui no Brasil só são divulgadas literatura estrangeira, de massa, que são traduzidas, é claro. Por causa do marketing, da Internet. Literatura brasileira não é divulgada. Tipo Paulo Coelho, Dalton Trevisan, ninguém lê eles atualmente. (Janete, 19 anos)

Eu acho que a forma como é escrita é diferente. O brasileiro se foca muito na... pelo menos a literatura que foi me indicada até agora, são literaturas antigas. A forma de escrever parece que é arrastado. Você não consegue ter aquela linearidade de leitura. (Pedro, 27 anos)

Olha... eu gosto de literatura estrangeira... eu li... eu até comprei porque eu gosto 
muito, $O$ caçador de pipas... eu li várias vezes. Até li um Harry Potter mas... não gostei muito não... porque... na verdade eu não gostei de coisas que não existe... em nada... não só em literatura... em filme... (...) Nem novela quando começa com essas coisas nada a ver... igual um robô falando... eu já não gosto. Não assisto. Eu não gosto de ficar pensando em coisas que não existem. Então... com relação à literatura por isso... Harry Potter, O Senhor dos Anéis... ai! (expressão de nojo)... animais que falam, que pensam... eu não gosto deste tipo de coisa. Quer dizer... não é essa na verdade a literatura estrangeira... mas é o que a gente tem contato. (...) Igual... do Edgar Allan Poe... eu fui descobrir no começo deste ano que existia... sabe? Então... se alguém não fala pra você... você não tem acesso. O que você tem acesso são os livros estrangeiros da mídia. (Priscila, 24 anos)

A preferência pela literatura estrangeira nos dois primeiros alunos está relacionada à divulgação do mercado editorial e à linguagem fácil, voltada para o consumo. Janete tem consciência de que a indústria editorial está por trás da venda de best-sellers e de que a maioria divulgada no Brasil é estrangeira. A aluna Priscila também percebe a influência da indústria cultural, de como as obras estrangeiras chegam até os brasileiros, no entanto, apesar de gostar de algumas obras - com exceção das obras com muita fantasia -, diz não ter 
preferência por essa literatura. Reconhece que a concepção de literatura estrangeira baseada principalmente em best-sellers ocorre devido à mídia, que favorece o contato dos brasileiros com estas obras mais lucrativas, enquanto clássicos como Poe só são conhecidos, muitas vezes, na graduação em Letras.

\section{CONSIDERAÇÕES FINAIS}

Nos últimos séculos, temos observado o aumento de produções narrativas com fins comerciais. Horkheimer e Adorno (1978) chamam o uso da cultura como mercadoria de "indústria cultural", pois, assim como outros estudiosos, acreditam que a literatura não deve ter um fim comercial. Muitos críticos literários afirmam que o discurso literário é não pragmático (EAGLETON, 1983), imotivado (HANSEN, 2005), gratuito (CANDIDO, 1985). O que é contraposto às características do best-seller.

Por isso, o termo "indústria cultural" tem sido muito empregado em pesquisas que focam literatura de mercado, destacando a influência dos meios de comunicação sobre as vendas de livros, logo, sobre as escolhas dos leitores. Muitas vezes, o público não escolhe realmente o que quer ler, mas é "convencido" pela mídia a fazê-lo.

A interpretação dos dados aponta o interesse de grande parte dos acadêmicos de Letras em ler best-sellers. Apesar de 
as obras serem marginalizadas pela universidade, é popular entre os jovens devido a fatores diversos, como a linguagem acessível e conteúdo envolvente. Os acadêmicos do primeiro ano, que recém concluíram o Ensino Médio, demonstram maior preferência por tais obras. Já os estudantes dos anos seguintes não citaram tantos títulos de best-sellers. Contudo, de modo geral, os participantes apresentaram uma visão distorcida de literatura estrangeira, atravessada pela influência forte da mídia e dos amigos, os quais, por sua vez, também foram influenciados direta ou indiretamente pela indústria cultural.

As escolhas de leituras dos participantes da pesquisa estão divididas entre a instituição de ensino e o mercado de consumo, porém a influência dos professores e da academia sobre suas leituras fora da universidade parece ser menor diante do mercado editorial: as leituras não obrigatórias são as marginalizadas. Devido a tais influências, exteriores à universidade, a concepção de literatura dos participantes também é afetada e mistura as perspectivas de críticos literários e as ditadas pela mídia.

\section{REFERÊNCIAS:}

André, Marli Eliza Dalmazo Afonso de. (1995). Etnografia da prática escolar. Campinas, São Paulo: Papirus.

Becker, Daniel (2003). O que é adolescência (13a ed.). São Paulo: Brasiliense. 
Eco, Umberto (1979). Apocalípticos e integrados. São Paulo: Perspectiva. Horkheimer, Max \& Adorno, Theodor W. (1978). A indústria cultural: o iluminismo como mistificação de massas (2a ed.). In Adorno et. al. Teoria da cultura de massa (p.159-204). Rio de Janeiro: Paz e Terra.

Mafra, Núbio Delanne Ferraz (2003). Leituras à revelia da escola. Londrina: Eduel.

Meier, Bruno (2011). Uma geração descobre o prazer de ler (n. 2217, p.98108). São Paulo: Revista Veja.

Mury, Gilbert (1974). Sociologia del publico literário. In, Robert Escarpit. Hacia una sociologia del hecho literario (p.205-218). Madrid: Edicusa.

Paes, José Paulo (1987). As dimensões da aventura. In Regina Zilberman (Org.). Os preferidos do público: os gêneros da literatura de massa (p.6575). Petrópolis: Editora Vozes.

Rocco, Maria Thereza Fraga (1992). Literatura/Ensino: uma problemática (2a ed.). São Paulo: Ática.

Sodré, Muniz (1985). Best-seller: a literatura de mercado. São Paulo: Ática. Triviños, Augusto Nibaldo Silva (1987). Introdução à pesquisa em ciências sociais: a pesquisa qualitativa em educação. São Paulo: Atlas.

Versiani, Zélia (2003). Escolhas literárias e julgamento de valor por leitores jovens. In Aparecida Paiva et. al. Literatura e letramento: espaços, suportes e interfaces (p.21-34). Belo Horizonte: Autêntica.

Daiane da Silva Lourenço - Professora de Língua Inglesa da Universidade Tecnológica Federal do Paraná, campus Francisco Beltrão. Mestre em Letras (UEM, 2012). Coordenadora do Centro Acadêmico de Línguas Estrangeiras Modernas. Membro do grupo de pesquisa Observatório Paranaense de Tecnologias de Informação e Comunicação e Sociedade. Contato: daianelourenco@utfpr.edu.br

Vera Helena Gomes Wielewicki - Professora associada na Universidade Estadual de Maringá, Departamento de Letras Modernas. Doutora em Letras pela FFLCH, USP e pós-doutora pela mesma instituição. Professora 
permanente do Programa de Pós-Graduação em Letras. É membro do GT da ANPOLL "Transculturalidade, Linguagem e Educação". Contato: vhgwielewicki@gmail.com

Recebido em 18 de dezembro de 2014. Aprovado em 11 de maio de 2015. 